\title{
O SIMULACRO DA ALTERIDADE EM PERSPECTIVA: COMENTÁRIOS ACERCA DE UMA ANÁLISE DISCURSIVA DE UM RITUAL DA IGREJA UNIVERSAL
}

Marcelo Tadvald ${ }^{1}$

O neopentecostalismo é, como sugere André Corten (1996), o mais poderoso dos novos movimentos religiosos. As igrejas conhecidas como neopentecostais constituem um verdadeiro fenômeno. A cada dia crescem em proporção vertiginosa e já se tornaram artigos brasileiros de exportação. A Igreja Universal do Reino de Deus (doravante IURD) consiste em um dos principais exemplos desse moderno tipo de organização religiosa. Fundada em 1977 pelo polêmico - e não menos cultuado por seus fiéis - Edir Macedo, que se autoproclamou Bispo dentro de sua Igreja, a IURD se notabilizou pelo enfrentamento dos diversos cultos religiosos de matriz africana espalhados pelo Brasil.

De fato, a Universal criou um culto que se realiza através de uma discursividade própria, alimentadapelo sincretismo, marca da discursividade das religiōes afro-brasileiras desde suas origens, quando aqui chegaram com os escravos que tiveram de adaptá-las à cosmologia cristã colonial. A discursividade iurdiana se impinge de uma autoridade que deve agregar sentido aos seus fiéis, de modo a não permitir re-interpretações de outras ordens, como parece ser o caso do espiritismo kardecista, por exemplo. Assim sendo, se, por um lado, nos parece insuficiente categorizar a IURD como fundamentalista, por outro, pode-se defini-la como um exemplo de "religião da emoção". Ou seja, como pudemos observar no trabalho de Jaçanã

\footnotetext{
${ }^{1}$ Programa de Pós-graduação em Antropologia Social, UFRGS. Pesquisador do Núcleo de Estudos da Religião (NER).
} 
Ribeiro, com o qual nos propomos a dialogar aqui, o culto da IURD aciona profundas estruturas emocionais e psicológicas de seus sujeitos-fiéis.

O discurso pentecostal é de um tipo que produz uma espécie de paixão (Corten, 1996). É essa paixão que, acima de tudo, garante a sua força. No caso da IURD, seu discurso se fundamentou através de um declarado ataque ao discurso das religióes afro. Do ponto de vista estratégico, tal medida de forma alguma se deu de maneira não intencional. Isto porque, como sabemos através de diversos estudos sobre o tema, tais igrejas "tocam" de maneira particular as camadas mais pobres da população. Não por acaso, este será seu público em potencial. De acordo com dados oriundos de pesquisas, e mesmo de censos oficiais, é sabido que as religióes afro no Brasil possuem uma maioria de participantes advindos também das camadas menos favorecidas da sociedade. E tal fato se explica por razões históricas inclusive. Transformar o "principal concorrente" em verdadei ro "inimigo" foi naturalmente realizado no caso da IURD. Outras igrejas, ao contrário, não adotaram tal estratégia, ao menos não da maneira como a IURD o faz.

O momento ritualístico - aquele em que devem ser observados os conjuntos de formalidades prescritas dentro de um mote cerimonial, ocasião em que tais categorias se realizam, se re-atualizam, agregam e fornecem sentido aos participantes - no caso da IURD, consiste, primordialmente, nas Sessões do Descarrego e nas Correntes de Libertação, dois momentos que podem ser agrupados sob o rótulo de sessôes de cura. A fim de procurar compreender as categorias estruturantes fornecidas pela instituição em questão e de que maneira tais categorias são apreendidas pelos sujeitos e manifestas por estes em suas visóes de mundo e comportamento, acreditamos ser pertinente uma análise dos discursos enunciados nos momentos ritualísticos que tais instituiçôes possam possuir. Tal procedimento nos permite desvelar de que maneira determinada instituição manifesta seus atributos primordiais procurando estabelecê-los para aqueles a quem ela se reporta. Este expediente analítico só pode ser utilizado em estudos acerca de instituições que possuem um determinado momento ritualístico bem determinado e que, de maneira indelével, consagra aquelas propostas que tal instituição se propõe desempenhar. No caso da IURD, tal tarefa encon- 
tra todos os subsídios necessários para a realização de tal expediente metodológico, pois, como toda instituição de caráter religioso, a IURD possui um ritual imprescindível para sua atuação que, além de ser extremamente discursivo, manifesta e realiza sua ideologia acercade diversos elementos,como sua concepção de cura, de fé, do bem, do mal, de conversão etc, ou seja, de todo um imaginário que deve ser compartilhado por seus fiéis. Por isso, o trabalho de Jaçanã Ribeiro vem contribuir diretamente para os estudos do campo da religião sobre a IURD que adquiriu, especialmente no curso das duas últimas décadas, proporções talvez muito maiores daquelas concebidas originalmente por seus idealizadores. A análise do discurso das sessóes de cura da IURD realizada pelo autor nos permitiu estabelecer algumas reflexões acerca deste tema que gostaríamos de compartilhar a seguir.

O corpo discursivo da IURD claramente se fundamenta através do corpo discursivo das religiōes afro. Ao atacar este último, o incorpora e o re-significa. De fato, é correto supor que o discurso da IURD se estabelece a partir de uma relação interdiscursiva com as religiōes afro. A forma pela qual se estabeleceu essa interdiscursividade teve no exorcismo um elemento importante do ponto de vista de uma celebração, haja vista que as categorias afro foram definidas como aquilo que se deve, em última instância, combater. Para realizar tal tarefa, a IURD celebra a força do Espírito Santo, que deve se opor ao mundo diabólico dos espíritos que existe nas religióes afro (Corten; Mary, 2000). Dado que tal igreja celebra uma concepção imanente de um poder superior (no caso, o Espírito Santo), este deve se manifestar nas sessōes de cura (exorcismo), e o único que possui a autoridade conferida para conclamá-lo trata-se, como está posto no trabalho de Ribeiro, do sujeito-bispo (ou sujeito-pasto r). São os rituais que conferem ao tempo e ao espaço sua dimensão de sagrado (Corten, 2004). O que se verifica em tais sessóes de cura da IURD é um verdadeiro campo de batalha onde é realizada uma guerra espiritual, onde está em jogo a luta pelo sagrado. Tendo como inimigo - nesta guerra santa proclamada pelos iurdianos - as religiōes afro, os exorcismos promovidos pelas sessões de cura assumi ram um caráter de "con tra-feitiço", graças à própria agregação das categorias discursivas combatidas.

Debates do NER, Porto Alegre, ANo 6, N. 7, P. 89-97, JAN./Jun. 2005 
O discurso que pode ser extraído de tais rituais (seja dos sujeitos-bispos, seja dos sujeitos-fiéis) demonstra não necessariamente uma polissemia, mas antes um corpo discursivo mais ou menos coeso construído através de uma relação dialógica estabelecida entre esses sujeitos. É interessante pensar que o papel do sujeito neste momento ritualístico pode lhe conferir maior ou menor autoridade no que tange a elaboração desse discurso, tendo o sujeito-bispo um papel mais privilegiado. Isso, contudo, não necessariamente transforma o enunciado como prioritariamente exterior ao sujeito, pois, como referido anteriormente, uma vez estabelecida uma relação dialógica, por mais que um dos sujeitos se encontre em uma posição mais privilegiada no sentido de conduzir os rumos de consolidação de um discurso, este jamais se realizará plenamente se não fizer sentido para o outro sujeito. $\mathrm{O}$ enunciável jamais poderá realizar-se exteriormente ao sujeito. $\mathrm{O}$ discurso iurdiano aciona uma espécie de vulnerabilidade intrínseca aos membros. O corpus discursivo vem de fora, é proporcionado pela IURD, mas este na verdade consiste numa apropriação e mesmo re-significação de um outro já interiorizadoanteriormente pelos membros, que pode ser aquele dos cultos afro ali combatidos, por exemplo. Ou do medo do castigo divino presente na cultura cristã que também pode ser acionado pela discursividade iurdiana, assim por diante.

De fato, e como bem resgatado pelo estudo de Jaçanã Ribeiro, o modelo que talvez dê melhor conta desse tipo de problema ainda consiste naquele proposto por Dominique Maingueneau (1984), que atenta para a análise de um interdiscurso dentro de um delimitado universo discursivo, campo discursivo e espaço discursivo, em que a identidade discursiva é constituída na relação com o outro, sem que necessariamente um corpo discursivo institucional esteja definindo de fato e de direito os discursos dos sujeitos. Se, por um lado, analisar o espaço ritual onde estes discursos são produzidos se torna condição para compreendê-los, do mesmo modo será preciso analisar de que maneira as pessoas incorporam e manifestam estes discursos. Será que, no exemplo da IURD, os sujeitos-fiéis o fazem da maneira preconizada pelos sujeitos-bispos (pela instituição)? Do ponto de vista deste último e de quem ali da platéia assiste ao ritual, possivelmente sim. Mas 
do ponto de vista dos sujeitos-fiéis tal questão se torna mais difícil de responder, isto porque as motivações que os levam a se comportar daquela maneira podem ser as mais variadas possíveis. Dentre estas existem aquelas que são esperadas pelo interlocutor sujeito-bispo, evidentemente. Mas pode haver outras, não menos importantes (e talvez até mais importantes), esperadas pelos sujeitos-fiéis entre si. Em qualquer jogo interativo, é imprescindível atentarmos para todas as possibilidades, já que todo e qualquer sujeito age de acordo com certas expectativas que ele projeta serem compartilhadas pelo outro.

O discurso institucional, através do ritual, tão somente possui o poder de conduzir as formulações discursivas. Isto não elimina o poder do sujeito-bispo de condutor desta formulação discursiva; pelo contrário, lhe garante a autoridade de possuí-lo. Por isso, é possível confundir sua voz com a de Deus, torná-lo o representante da palavra divina. Dentro do ritual, o sujeito-bispo apenas representa performatica mente tais atributos e, através dessa autoridade que o ritual e que a instituição lhe confere, ele pode reproduzir (e mesmo construir) um discurso desejado. Para além do ritual é que as motivações dos sujeitos-fié is em ajudar a construção de tal discurso devem se apresentar. Mas é apenas no ritual que tais motivações podem ser percebidas.

A dualidade do sujeito-fiel, apontada no estudo de Ribeiro, nada mais é do que resultado da pró pria dualidade discursiva que existe na interdiscursividade característica da IURD, que prima pela inversão em um sentido pejorativo das categorias existentes nas religiões afro. Por isso é que se torna possível, por exemplo, caracterizar uma entidade do culto afro como o diabo cristão, encarnação de todo o mal que se possa imaginar. Lembremos que o Brasil possui ainda uma importante matriz religiosa católica. Tal matriz também é acionada pelo discurso iurdiano.

Pensar em uma categoria de simulacro para entender o processo perseguido pela IURD com relação aos cultos afro é extremamente procedente, pois, de fato, a IURD acabou produzindo entidades originalmente afro com características próprias. Recordo de uma sessão de descarrego que participei em que, ao ser interpelado pelo bispo com a pergunta: "fala! Quem 
está aî?”, um fiel respondeu aos gritos: “é Iemanjá!", com uma voz grave e soturna. Quem já teve a oportunidade de presenciar a manifestação dessa entidade em alguma sessão de um culto afro sabe que tal entidade não se caracteriza dessa maneira. Iemanjá normalmente se manifesta de forma suave e gentil.

Alejandro Frigerio (1993) já sugeriu a existência de alguma relação entre situação emocional e social, e conversão. Isto talvez contribua para se compreender outro ponto levantado pelo estudo de Ribeiro. $\mathrm{O}$ autor menciona o fato, comum nas sessões de cura e nos processo de exorcismo, de os sujeitos-bispos, a fim de expulsarem os encostos, freqüentemente se dirigirem aos sujeitos-encostos de maneira debochada, humilhante até. Para o autor, tal fenômeno não incide maiores constrangimentos para o sujeitofiel, pois, no momento ritual (lá no altar, quando isso ocorre), existe uma clara separação entre personalidades diferentes. Os escárnios são dirigidos ao encosto. Ele é quem merece o repúdio, não o sujeito-fiel. Mas o que levaria o sujeito-fiel a se dispor a este tipo de situação? Dentro da discursividade da IURD, seria o encosto que se manifesta graças ao poder do Espírito Santo ali presente. Mas, quanto aos sujeitos-fiéis, seria somente por tal motivo?

O ritual permite esse tipo de re-significação de uma situação aprioristicamente vexatória para o sujeito. Como pude observar em sessões de descarrego que participei, tal fenômeno pode conferir certa visibilidade social para aqueles sujeitos dentro desta comunidade emocional do qual fazem parte. Lembremos que tais sujeitos possivelmente não devem possuir muita visibilidade social fora dali. Não pretendo essencializar demais a discussão, mas lembremos que entre as classes populares, incorrer numa carreira marginal e de violência muitas vezes serve justamente para fornecer certa visibilidade social para alguns membros. Manifestar um encosto na sessão do descarrego pode ser compreendido a partir desse aspecto, uma vez que é empiricamente demonstrável que a maioria absoluta das pessoas que recebem os encostos e que se precipitam ao palco advêm das camadas menos favorecidas da sociedade. No momento em que o sujeito-bispo esbraveja algo do tipo: "manifesta!", todas as atençôes se voltam para os sujeitos- 
encostos, ou, dito de outra maneira, para as pessoas que manifestam o encosto. Ainda que o ritual assim o diga, elas não deixam de ser o José, o João, a Maria. Todo o culto percebe isso, e os percebe também. Certa vez, numa sessão do descarrego, duas fileiras ao meu lado, absolutamente do nada (o bispo já havia expulsado alguns encostos e falava sobre outro assunto), uma mulher começou a grunhir alto. O bispo então disse: "olha aí os exus se manifestando". Uma obreira correu e agarrou a mulher, deixando-a sentada, contida. O bispo então falou: "tá amarrado, tá amarrado!" As pessoas começaram a simbolizar isso com as mãos, passando uma sobre a outra, circularmente. Depois que a obreira se afastou ela permaneceu lá, sentada, impassível, como se nada tivesse acontecido. Permaneci observando e pude constatar que muitos fiéis seguiram olhando para aquela mulher que, ao que parece, havia ido ao culto sozinha. Naquela noite, estimo ter participado da sessão junto com cerca de duas mil pessoas. Para toda aquela gente, esta mulher saiu do anonimato, ao menos por breves instantes.

Do mesmo modo, o estudo de Ribeiro demonstra a existência de certos níveis de resistência que configuram a negatividade e o antagonismo das entidades no momento do exorcismo, quando os sujeitos-encostos resolvem enfrentar a autoridade dos sujeitos-bispos. O que esta resistência tem a nos dizer? Ela serve para agregar valor à visibilidade social do sujeito-fiel? Trata-se de uma resistência do sujeito-fiel perante o ataque iurdiano a uma entidade que já foi cultuada por si em outro momento? Para o autor, constituem estratégias adotadas pelos sujeitos-encostos como resistência ao simulacro, mas creio que a dimensão da visibilidade social permitiria outro nível de argüição.

Os movimentos religiosos possuem a capacidade de "construção do eu". Da mesma man eira, a conversão individual consiste nu ma "construção do eu" que se realiza através de uma luta espiritual (Corten, 2004). Tal prerrogativa aclara uma definição maior do que consiste um dos principais projetos da IURD, ou seja, a da construção de um "eu”, sujeito-fiel. Portanto, faz sentido para sujeitos-fiéis em potencial a apropriação pela IURD de elementos das religiōes afro, quando tais sujeitos compartilham desses significados, seja por já terem participado de algum culto afro, seja por 
acreditarem estarem à mercê das influências de um encosto, ou dos males de um "trabalho" dirigido a si, ou seja, por tudo isso. Lá na igreja, tais sujeitos encontrarão muitos que em diversos particulares se assemelham a si. Os sentimentos de comunhão, de uma identidadecoletiva (Champion;HervieuLéger, 1990) são plenamente acionados nas sessões de cura da IURD.

Como bem demonstrou o trabalho de A. Corten e de A. Mary (2000), discursos como aquele proferido pela IURD mobilizam com mais facilidade o imaginário de culturas religiosas heterogêneas, como é o caso brasileiro. $\mathrm{O}$ problema é quando tais discursos denotam uma verdadeira intolerância religiosa, chegando a incentivar uma espécie de perseguição, estigmatização e alarido comunitário. Apenas para se ter um exemplo, recentemente a IURD foi condenada pela justiça a pagar uma indenização de $\mathrm{R} \$ 960$ mil à família de mãe-de-santo Regina Bochicchio, de Salvador (BA), por danos morais e uso indevido de imagem de Mãe Gilda (sacerdotisa morta em janeiro de 2000) no periódico oficial da IURD. Conforme matéria veiculada no Jornal A Tarde, numa edição de 1999 do Jornal Universal, Mãe Gilda aparece numa foto (publicada pela revista Veja sete anos antes) com uma tarja preta cobrindo seu rosto e a frase: "Macumbeiros e charlatóes lesam bolso e vida de cliente". Além da indenização, a Igreja Universal e sua gráfica deveráo publicar a sentença, em duas edições consecutivas, na capa do Jornal Universal. "Para o povo do candomblé, não é o dinheiro que importa neste caso, mas só pelo fato de a gente colocar a Universal no banco dos réus já é uma grande vitória. Se minha mãe estivesse aqui...", diz, emocionada, Jaciara San tos Ribeiro, 35 anos, filha biológica de Mãe Gilda e que assumiu o Terreiro Ilê Axé Abassá de Ogum depois da morte de sua mãe, em janeiro de 2000. A ialorixá e seus irmãos, bem como a comunidade do candomblé, acreditam que, na verdade, Mãe Gilda, que tinha 65 anos, morreu "de desgosto" depois de ter visto sua foto no Jornal Universal, ligando sua imagem ao charlatanismo. Para se ter uma idéia, depois da publicação,evangélicos chegaram a invadir o terreirode Mãe Gilda, com o intuito de exorcizála. "Ela (Mãe Gilda), que não tinha nenhum problemade saúde, morreu de infarto fulminante. Minha mãe morreu, na verdade, por causa do desgosto que o uso da imagem dela causou", crê Jaciara (Jornal A Tarde, 07/07/2005). 
Um estudo como o de Ribeiro seguramente vem somar nesta discussão, já que proporciona um desvelar de diversas minúcias que compõe este quadro discursivo que contribui para uma formulação religiosa no mínimo polêmica.

\section{REFERÊNCIAS}

CORTEN, André. Pentecôtisme et politique en Amérique latine. In: Problèmes d'Amérique latine. N. 24, 1997, p. 17-32.

CORTEN, André; MARY, André. Imaginairespolitiques etpentecôtismes : Afrique/ Amérique latine. Paris: Karthala, 2000.

CORTEN, André. Pentecôtismes: Immanence et transnationalisation. Paris: Archives de Sciences Sociales des Religions, 2004. Consultado em www.ehess.fr/centres/ceifrlindex. html CHAMPION, Françoise; HERVIEU-LÉGER, Danièle. Présentation. In: (vários) De l'émotion en religion: Renouveaux et traditions. Paris: Centurion, 1990.

FRIGERIO, Alejandro. Perspectivas actualessobre conversion, deconversion y "lavado de cere bro" en nuevos movimientos religiosos. In: FRIGERIO, Alejandro (org). Nuevos movimientos religiosos y ciencias sociales. Buenos Aires: Centro Editor de América Latina, 1993.

Jornal A Tarde, Salvador, 07/07/2005.

MAINGUENEAU, Dominique. Genèses du discours. Bruxelas: Pierre Mardaga Editeur, 1984. 
